\title{
Trabalhonecessário
}

Issn: 1808 - 799X

ano 13 , número $21-2015$

\section{PEDAGOGIA DAS COMPETÊNCIAS PARA A EDUCAÇÃO \\ PROFISSIONALIZANTE DE NÍVEL SUPERIOR: SÍNTESE, CONCEITO E CRÍTICA ${ }^{1}$}

José Deribaldo Gomes dos Santos²

\section{Resumo}

O artigo apresenta uma análise teórica sintética sobre a relação existente entre as Diretrizes Curriculares Nacionais Gerais para a Educação Profissional de Nível Tecnológico e alguns autores que se dedicam teórica e empiricamente sobre a "pedagogia das competências" no ensino superior. Do ponto de vista teórico, a comunicação põe em debate a produção acadêmica acerca do paradigma da qualificação e o seu deslocamento discursivo sobre a categoria da competência. A partir desse contexto, e embasado na relação trabalho e educação dentro da tradição marxista, o artigo se debruça especialmente sobre as apropriações acerca do conceito de pedagogia das competências, para considerar, mesmo que de forma abreviada, a existência de interesses capitalistas em demandar para o ensino superior não universitário uma determinada pedagogia, afinada com interesses mercantis.

\footnotetext{
10 artigo é fruto das reflexões contidas na pesquisa Ensino médio integrado no estado do Ceará: uma análise sobre a proposta pedagógica do empreendedorismo empresarial na escola pública, que conta com financiamento da Fundação Cearense de Apoio ao Desenvolvimento Científico e Tecnológico (FUNCAP) e do Conselho Nacional de Desenvolvimento Científico e Tecnológico (CNPq).

2 Doutor em educação, professor do Programa de Pós-Graduação em Educação da Universidade Estadual do Ceará (PPGE-UECE), do Mestrado Acadêmico Intercampi em Educação e Ensino (MAIE-UECE) e da Faculdade de Educação, Ciências e Letras do Sertão Central (FECLESCUECE); bolsista de estágio pós-doutoral da CAPES. E-mail: deribaldo.santos@uece.br
} 


\section{Trabalhonecessário}

Issn: 1808 - 799X

ano 13, número $21-2015$

Palavras-chaves: Pedagogia das competências. Educação profissionalizante. Política pública educativa. Graduação tecnológica.

\section{Resumen}

El artículo presenta un análisis teórico que intenta hacer una síntesis de la relación entre las directrices nacionales generales para el Nivel Tecnológico de Formación Profesional, bien como en artículos de algunos autores que se ocupan teórica y empíricamente en la "pedagogía de las habilidades" en la educación superior. Desde un punto de vista teórico, la ponencia discutí el debate académico sobre la producción de paradigma calificación y su cambio discursivo en la categoría de habilidad. A partir de este contexto y con base en la relación entre el trabajo y la educación dentro de la tradición marxista, este ensayo explora especialmente la apropiación del concepto de habilidades pedagógicas, para considerar, brevemente, la existencia de los intereses capitalistas en la demanda de la educación superior por una pedagogía universitaria específica en sintonía con los intereses comerciales.

Palabras claves: Pedagogía de las habilidades. Educación vocacional. Políticas públicas para la Educación. Graduación Tecnológico.

\section{Abstract}

This article presents a synthetic theoretic analysis of the link between the "General Nationals Curriculum Guidelines" to the Professional Education of Tech Level and some authors engaged, theoretically and empirically, in the "pedagogy of competencies" in undergraduate schools. In the theoretic perspective, the present 


\section{Trabalhonecessário}

Issn: 1808 - 799X

ano 13, número $21-2015$

dialogue discuses on the production academic in the qualification paradigm and its discursive shift on the category of competence. Considering this context and based in the link between work and education in the Marxist tradition, this article focuses especially on the appropriation of the concept of "pedagogy of competencies", to consider, even in abbreviated form, the existence of capitalist interests in demand for non-university hight school a particular pedagogy in conformation with mercantile interests.

Keywords: Pedagogy of competences; Professional education; Educational public policies; Technological graduation.

\section{Introdução}

Em articulação com um modelo de gerenciamento afinado com os padrões da racionalidade produtivista que, por sua vez, aponta para a concepção administrativa chamada de qualidade total, a escola passou a absorver a defesa da construção de um currículo baseado na pedagogia das competências. Tal proposta educativa, como entendem seus defensores, teria competência para desenvolver, no estudante, valores "inovadores" voltados para uma suposta qualificação profissional, reordenada a gosto dos imperativos da chamada "era tecnológica". A principal justificativa para a implantação dessa "nova" concepção escolar - proclamada por alguns documentos oficiais, empresários, jornalistas e parte da intelectualidade - seria o ajuizamento de que o complexo educativo precisa se adaptar para atender às necessidades capitalistas dos contemporâneos problemas no dito mundo produtivo.

No repertório dos inúmeros novos paradigmas educacionais, a pedagogia das competências merece uma atenção especial no que se refere à análise do 


\section{Trabalhonecessário}

Issn: 1808 - 799X

ano 13, número $21-2015$

currículo, predominante na expansão do Ensino Superior Brasileiro (ESB). De modo destacado, essa proposta curricular orienta, prioritariamente, a expansão que se verificou nos últimos anos através da designada graduação tecnológica. Posicionado nesse sintético contexto este artigo intenciona debater a relação existente entre a pedagogia das competências e o currículo dos cursos de graduação tecnológica no Brasil. Mesmo sem pretender esgotar toda a polêmica que cerca a discussão, examinaremos, de modo abreviado, os elementos dessa pedagogia mais pertinentes acerca do que se convencionou chamar de Ensino Superior Não Universitário (ESNU). Tal debate será apreendido aqui em sua articulação com a lógica privatista presente na atualidade da universidade brasileira. A concepção e as matrizes que originaram a ideologia das competências no campo pedagógico e, em especial, no Ensino Superior (ES), serão tratadas nas seções que estruturam a organização do presente texto.

Assim, para que a leitura possa se desenvolver com mais consistência, precisamos adiantar o que se entende no Brasil por graduação tecnológica. Para o Ministério da Educação (MEC) são cursos superiores com duração reduzida e currículos flexíveis que devem procurar formar o tecnólogo para atender às demandas da economia, devendo abranger áreas especializadas, aliando teoria e prática. Para o ministério a estrutura desses cursos devem ter, no mínimo, dois anos e destinam-se ao atendimento de uma clientela que tenha concluído o ensino médio ou equivalente (BRASIL; MEC; CNE, 2002). Interessante observar que, perante a exigência destacadamente mercadológica de tal modelo de ES, sua proposta formativa distancia-se dos bacharelados e licenciaturas que se alinhavam, essencialmente, ao que se convencionou chamar de formação universitária. Por esse motivo, as graduações tecnológicas são enquadradas dentro do que se chama de ESNU.

Como esta comunicação segue as características de um estudo de caráter teórico, bibliográfico e documental, do ponto de vista do método, visitaremos 


\section{Trabalhonecessário}

Issn: 1808 - 799X

ano 13, número $21-2015$

algumas produções que analisam os currículos desses cursos, bem como alguns documentos oficiais que se pronunciam sobre a importância das competências para o currículo, principalmente aqueles referentes aos cursos profissionalizantes. Para efeito desta exposição, optamos por recortar as pesquisas de Lima (2011), Souza (2012) e Takahashi e Amorim (2008). O primeiro dos autores citados analisou, em sua dissertação de mestrado, a aprendizagem por competência de dois cursos de graduação tecnológica ${ }^{3}$. A tese de doutorado de Souza (2012, p. 09) pretendeu, entre outros objetivos, "caracterizar a configuração dos cursos superiores de tecnologia no interior do processo de democratização do acesso ao ensino superior brasileiro". Takahashi e Amorim (2008), por sua vez, foram escolhidos por serem entusiastas das competências e do "empreendedorismo" utilizados nos currículos dos cursos de graduação tecnológica.

Quanto aos documentos oficiais, referentes a tais cursos, escolhemos o parecer $n^{\circ}$ 29/2002, do Conselho Nacional de Educação (CNE), regulador das Diretrizes Curriculares Nacionais Gerais para a Educação Profissional de Nível Tecnológico, e a resolução nº 04/1999, do CNE, visto que este texto, conforme registrou Nomeriano (2007), instituiu as Diretrizes Curriculares Nacionais para a Educação Profissional de Nível Técnico e trouxe para a legislação educativa a expressão "competência profissional"4.

A partir desse ponto procederemos nosso debate procurando submeter tal

\footnotetext{
${ }^{3}$ A pesquisa de Lima (2011) priorizou dois cursos tecnológicos: Gestão da Tecnologia da Informação (GTI) e Tecnologia em Análise e Desenvolvimento de Sistemas (TADS), oferecidos pelo Instituto Federal de Educação, Ciência e Tecnologia de Goiás (IF/GO), campus de Urauna. O pesquisador analisou os Projetos Pedagógicos dos Cursos (PPCs) para verificar a importância das competências em seus currículos.

${ }^{4}$ No interior do MEC o debate em torno do modelo de competências ganhou ressalto através da Resolução CNE/CP no 03/2002 que instituiu as Diretrizes Curriculares Nacionais Gerais para a organização e funcionamento dos cursos superiores de tecnologia. Esse dispositivo legal, entre outros elementos contextuais, alimentaram a discussão sobre tal modelo ao ponto do Ministério promulgar o Parecer $n^{\circ}$ CNE/CES $n^{\circ} 277 / 2006$, que passa a orientar uma nova forma de organização da Educação Profissional e Tecnológica de graduação. Dois anos depois foi a vez da Lei $\mathrm{n}^{\circ} 11.741 / 2008$ alterar o capítulo III da LDB que passa a ser denominado "Da Educação Profissional e Tecnológica".
} 


\section{Trabalhonecessário}

Issn: 1808 - 799X

ano 13, número $21-2015$

revisão à crítica marxista. No intuito de desvelar o que a aparência fenomênica dos fatos encobre em sua essência, buscaremos descortinar o obscurecido, propondo apontar para além do caoticamente aparente, ou seja, o que se encontra subjacente aos interesses dos contornos de uma sociedade dividida em classes. Sem pretensões de fechar a discussão esperamos contribuir com um melhor aclaramento sobre as atuais propostas de alargamento do ES, para onde aponta tal expansão e qual a sua orientação.

\section{As intermitências da pedagogia das competências}

Nas últimas décadas, variadas e novas teorias educacionais ocuparam 0 arco das discussões curriculares. A escola teria que se adaptar a esses "inovadores" modelos formados pelos, assim chamados, novos paradigmas educativos. De maneira geral, eles surgem com a proposta de resolver os problemas da esfera educacional e contam com a adesão dos organismos internacionais, entre outras características. Com a chamada pedagogia das competências não é diferente. Ela aparece e logo ganha foro de relevo no debate científico que cerca a educação, adquirindo destacada importância nas políticas públicas. Dentro dessa obscura névoa povoada por vários novos antídotos apresentados para a escola, a pedagogia das competências reedita para 0 complexo educativo o pretensioso papel de poder resolver uma grande gama de questões sociais geradas fora da pedagogia. Esse é o contexto em que o interior da educação é chamado a dar conta de problemas gerados muito além de seu escopo, que se enraízam na própria trama de contradições do capital em crise profunda.

Ao investigar os documentos oficiais percebemos que eles são um manancial de elogios aos novos paradigmas educativos e, em especial, à 


\title{
Trabalhonecessário
}

Issn: 1808 - 799X

ano 13, número $21-2015$

pedagogia das competências ${ }^{5}$. No Brasil, segundo registrou Nomeriano (2007), a resolução $\mathrm{n}^{\circ} 04$ do CNE registra em seu artigo $6^{\circ}$ o seguinte: "entende-se por competência profissional a capacidade de mobilizar, articular e colocar em ação, valores, conhecimentos e habilidades necessários para o desenvolvimento eficiente e eficaz de atividades requeridas pela natureza do trabalho". (BRASIL; MEC; CNE, 1999, p. 2). Já o parecer $n^{\circ} 29 / 2002$ do CNE, também conhecido como Diretrizes Curriculares Nacionais Gerais para a Educação Profissional de Nível Tecnológico, se pronuncia da seguinte maneira sobre tal paradigma:

\begin{abstract}
Emerge, no novo paradigma da educação e, de forma mais marcante, na educação profissional, o conceito de competência, mesmo que ainda polêmico, como elemento orientador de currículos, estes encarados como conjuntos integrados e articulados de situações-meio, pedagogicamente concebidos e organizados para promover aprendizagens profissionais significativas. Currículos, portanto, não são mais centrados em conteúdos ou necessariamente traduzidos em grades de disciplinas. A nova educação profissional desloca o foco do trabalho educacional do ensinar para o aprender, do que vai ser ensinado para $o$ que é preciso aprender no mundo contemporâneo e futuro. (BRASIL; MEC; CNE, 2002, p. 15).
\end{abstract}

Sobre os currículos escolares dos cursos médio-profissionalizantes, bem como dos cursos superiores de tecnologia ${ }^{6}$, o documento afirma que estes

\footnotetext{
${ }^{5}$ A palavra "competência" e seu plural aparecerem grafadas em um total de 87 vezes no parecer n 29/2002 do CNE. Já a expressão "competências profissionais" está marcada por 38 vezes no mesmo documento (BARSIL; MEC; CNE, 2002).

${ }^{6}$ Os países latino-americanos de língua espanhola, de forma geral, denominam as instituições que ofertam esses cursos de Instuciones de educacion superior no universitaria. Contudo, conforme informa o documento Informe sobre la educación superior en América Latina y el Caribe 20002005: La metamorfosis de la educación superior elaborado pela Unesco; IESALC (2006), em alguns países desse continente também se encontram a denominação de cursos politécnicos, a exemplo do Panamá, mesma nomenclatura utilizada em Portugal. No Brasil, a história desse subsistema já registrou termos distintos: cursos de engenharia curta, graduação tecnológica, graduação em tecnologia, cursos superiores de tecnologia (CSTs), cursos tecnológicos e, simplesmente, tecnológicos, entre algumas outras nomenclaturas. Podemos adiantar que a expressão Ensino Superior Não Universitário (ESNU) não se restringe somente aos cursos de graduação em tecnologia. Confere mais ao real considerar que o ESNU é formado por uma gama de cursos que se afastam de uma formação essencialmente universitária, cuja participação da
} 


\section{Trabalhonecessário}

Issn: 1808 - 799X

ano 13, número $21-2015$

"devem ser centrados no compromisso institucional com o desenvolvimento das competências profissionais" (BRASIL; MEC; CNE, 2002, p. 15).

Sem sequer adiantar alguma preocupação em relação à trama que envolve o complexo educativo pelas necessidades do capital, o texto oficial é farto em defender uma graduação tecnológica como solução para os problemas da qualificação da mão de obra demandada pelo onipresente mercado de trabalho e que ainda favoreça o combate ao desemprego. No texto em análise não há qualquer debate sobre a ambivalência da tecnologia; ao contrário, a proliferação das chamadas novas tecnologias é apresentada como um fator pelo qual essas graduações precisam adaptar seus currículos às competências. Assim, em seu artigo $1^{\circ}$, parágrafo único, o texto resolve que a educação profissional de nível tecnológico deve estar integrada às diferentes formas de educação, ao trabalho, à ciência e à tecnologia, objetivando "garantir aos cidadãos o direito à aquisição de competências profissionais que os tornem aptos para a inserção em setores profissionais nos quais haja utilização de tecnologias. Além disso, o primeiro parágrafo do artigo $6^{\circ}$ diz que a "organização curricular compreenderá as competências profissionais tecnológicas, gerais e específicas, incluindo os fundamentos científicos e humanísticos necessários ao desempenho profissional do graduado em tecnologia". Para não nos deixar sem uma definição do que é competência profissional o parágrafo único do artigo $7^{\circ}$ a define como "a capacidade pessoal de mobilizar, articular e colocar em ação conhecimentos, habilidades, atitudes e valores necessários para o desempenho eficiente e eficaz de atividades requeridas pela natureza do trabalho e pelo desenvolvimento tecnológico". (BRASIL; MEC; CNE, 2002, p. 41-3).

Mas não apenas nos textos oficiais encontramos otimismo com esse novo arranjo curricular. Diversas pesquisas se empenham em encontrar saídas propositivas para a pedagogia das competências. Ricardo Cirino de Lima (2011)

graduação tecnológica é privilegiada.

TrabalhoNecessário - www.uff.br/trabalhonecessario; Ano 13, No 21/2015. 


\section{Trabalhonecessário}

Issn: 1808 - 799X

ano 13, número $21-2015$

fez interessante esforço em sua exposição para se parecer elegante ao defender a pedagogia das competências. Depois de fazer um recorte sobre o debate, tendo como teoria principal as pesquisas do sociólogo suíço Philippe Perrenoud, Lima (2011, p. 50), procurando aliviar suas poucas críticas feitas a esse paradigma, conclui o seguinte: "De qualquer forma, como sempre ocorreu, a ruptura de paradigmas provoca polêmicas e, felizmente, amplas discussões que, no caso, só poderão ser benéficas para todos os atores envolvidos". O autor critica, ainda, as investigações de Neise Deluiz (1995), afirmando que a posição partilhada por esta pesquisadora é parcial e incompleta. Na realidade, Lima (2011, p. 40-1) afirma que "o que se busca com a visão por competência é a criação de vínculos entre empresa, empregados e empregadores, ampliando o envolvimento desses atores para além do horário formal de trabalho". O pesquisador acredita que o conceito de competência está contribuindo também para valorizar o indivíduo humano e, a partir de sua utilização, o sujeito não é apenas mais um funcionário, mas alguém com capacidade para se autodesenvolver, tornando-se um parceiro fundamental dentro das atividades da empresa. Os funcionários que apresentarem essa parceria, segundo Lima (2011), devem obter investimentos dos gestores e, principalmente, maior poder de participação acerca das decisões e sobre as estratégias de organização. Para justificar sua posição o autor não deixa dúvida quanto à sua tomada de posição a favor das empresas capitalistas, justificando da seguinte maneira: "A gestão por competência possibilita às empresas vencerem os desafios do mundo globalizado e competitivo em que vivemos, pois seu objetivo é tornar as pessoas mais competentes para que possam desenvolver seus trabalhos com maior sucesso e maior eficácia". (LIMA, 2001, p. 42).

No entendimento de Lima (2001) incluir a prática e a experiência como elementos auxiliadores da construção das competências é o mesmo que aproximar as concepções de Philippe Perrenoud às teses de Jacques Delors. A sua justificativa para essa identidade está no fato de que os propalados quatro 


\section{Trabalhonecessário}

Issn: 1808 - 799X

ano 13 , número $21-2015$

pilares da educação, defendidos por Delors, "não se restringem à educação formal, mas estendem-se a todas as formas de educação que ocorrem ao longo da vida". (LIMA, 2001, p. 44).

Lima (2011, p. 48-9) considera que as competências são uma forma de preparação do indivíduo para "enfrentar com sucesso os imprevistos e os desafios que lhe serão colocados ao longo da vida". É interessante registrar a afirmação desse autor sobre esse paradigma ser propício para formar o sujeito na escola, assim como no que ele chama de "mundo do trabalho"7. Nessas duas esferas, como aprofunda Lima (2011, p. 49), tanto os defensores das competências como seus críticos utilizam "argumentos importantes, que não podem ser ignorados em uma análise qualitativa da adoção ou não das competências como referenciais para o trabalho ou para a educação". Não obstante, para o autor, a "novidade" da proposta apresentada pela pedagogia das competências é que ela rompe justamente com um dos pilares utilizados pelas teses que a criticam. Com efeito, Lima (2011, p. 49) reafirma que essa nova propositura pedagógica se adapta "tanto para o trabalho quanto para a educação", por isso as críticas sobre ela "perderam um pouco de sua argumentação".

Já em suas conclusões, o autor indica que a pedagogia das competências surge para orientar o "que se convencionou chamar 'saber fazer' com foco nas competências e nas aprendizagens". Esse pesquisador, para dar respaldo teórico

\footnotetext{
${ }^{7}$ Sobre a ambivalência dessa categoria, vale a pena observar a seguinte consideração de Lessa (2013, p. 11): "Não é raro que uma dada noção apenas possa cumprir sua função ideológica se for imprecisa. Isto é mais frequente, como fenômeno ideológico, do que pode parecer à primeira vista. Considere-se, por exemplo, o termo 'mundo do trabalho'. Atua, na maior parte das vezes, como substituto da categoria, precisa e cientificamente estabelecida, de relações de produção. Sua enorme imprecisão possibilita que adquira, não apenas entre autores distintos, mas também no interior de um mesmo texto de um mesmo autor, significados tão distintos quanto o local de trabalho (que pode ser do escritório à fábrica, dos shopping centers a uma repartição estatal), a linha de montagem, a totalidade das atividades produtivas de uma sociedade ou da humanidade; uma postura de classe, como na expressão mundo do trabalho versus o mundo do capital, o sujeito revolucionário etc. Sugere, mais do que conceitua. No debate de ideias em uma sociedade de classes, toda imprecisão serve à classe dominante; sendo as ideias dominantes aquelas da classe dominante, as imprecisões tendem a ser interpretadas no sentido mais adequado a esta última".
} 


\section{Trabalhonecessário}

Issn: 1808 - 799X

ano 13, número $21-2015$

a sua investigação, repete o mantra composto por Delors e explica em que consiste tal proposta: aprender a conhecer, fazer, conviver e ser. Admitindo haver forte influência de tais pressupostos sobre os currículos das graduações tecnológicas, ele argumenta que esses cursos "mantém uma estreita relação com o mundo do trabalho globalizado, sempre muito competitivo e exigente nas cobranças por um novo tipo de trabalhador: flexível, prático, competente, criativo, comunicativo e com domínio das tecnologias de informação e comunicação." (LIMA, 2011, p. 130, grifos nossos).

Apesar de seu entusiasmo em defender os preceitos pedagógicos dos organismos internacionais sobre a educação superior oferecida aos trabalhadores e seus filhos, o investigador vê-se obrigado a explicar o insucesso da aquisição das competências nos dois cursos de graduação tecnológica que foram objetos de sua pesquisa. Pelas suas inferências ficou claro que, em ambos os casos, o projeto político dos cursos analisados é o vilão do problema e não as competências profissionais que Ihes servem de base. Lima (2011, p. 136) conclui que as ementas "não se fundamentam no mercado atual local/global". Com relação à "proporção de empregabilidade" vinculada diretamente à área de formação tecnológica, ambos os cursos foram avaliados com índices de até $25 \%$. Isto é, apenas um quarto dos respondentes dos dois cursos investigados acredita que sua formação tem ligação direta com um emprego.

As considerações teóricas e a revelação dos dados empíricos desta dissertação evidenciam os limites decorrentes de uma orientação legal que tem estimulado certa expectativa e possibilidade de formação de um profissional qualificado em menor tempo, garantia de empregabilidade, no intuito de atender as necessidades de mercado de trabalho. Podemos inferir que, no olhar dos sujeitos que participaram da pesquisa, a aprendizagem das competências e a empregabilidades que permeiam os discursos em relação aos cursos tecnológicos não condizem com 


\section{Trabalhonecessário}

Issn: 1808 - 799X

ano 13 , número $21-2015$

a realidade, pois as estratégias de redução do tempo e maior carga horária para as disciplinas selecionadas como específicas não estão garantindo efetivamente tais propósitos. (LIMA, 2011, p. 136).

Em linhas gerais, seguindo a mesma orientação da pesquisa de Lima (2011), mesmo com suas variações, o estudo de Souza (2012) procura defender as competências como recurso curricular para o ES. Sua pesquisa toma por base as considerações do entusiasta da privatização e aligeiramento do $E S$, a saber, o sociólogo Simon Schwartzmans. Nessa esteira, Souza (2012) argumenta que em muitos países a dilatação da educação superior ocorre paralelamente acompanhada de uma variação institucional, através do oferecimento de cursos distintos a diferentes clientelas. Souza (2012) advoga ainda que, do ponto de vista estritamente técnico e funcional, é possível pensar que as distinções proporcionadas pelas graduações tecnológicas podem responder às necessidades formativas de diferentes pessoas, dotadas de várias competências, a fim de preencher a grande variedade de ocupações e postos de trabalho existentes.

Para justificar a crença de que falta emprego apenas para quem não é "qualificado", Souza (2012) busca exemplificar que outros países já optaram por reformular seu ES com apoio na pedagogia das competências, citando, como exemplo, os casos dos Estados Unidos, Japão, Nova Zelândia, México e Reino Unido.

Souza (2012) procura explicar o caso do Reino Unido utilizando as pesquisas de Takahashi e Amorim (2008, p. 214) que afirmam:

[...] uma série de modificações no seu sistema educacional nos últimos anos, a fim de equalizar o percurso acadêmico e profissional. Uma delas foi a criação de rotas alternativas para a educação de nível superior, baseada em habilidades e competências voltadas para a prática profissional no mercado de trabalho. Estes cursos, que proveem uma qualificação de nível 


\section{Trabalhonecessário}

Issn: 1808 - 799X

ano 13, número $21-2015$

superior, podem ser de um ano (Higher National Certificate - HNC) ou de dois anos (Higher National Diploma - HND) e possibilitam que o estudante ingresse no $2^{\circ}$ ou no $3^{\circ}$ ano de um curso de bacharelado. Outra mudança foi a criação dos foundation degrees, que também são qualificações de ensino de nível superior voltadas para competências e habilidades do mercado de trabalho em diversas áreas. Estes cursos, assim como os HND's, apresentam mais 1.100 opções, estão num nível intermediário dentro da estrutura de ensino de nível superior (que vai até o bacharelado com 360 créditos), e são compostos de 240 créditos. Os cursos profissionalizantes são ofertados pelos colleges, chamados de Colleges of Further and Higher Education. Estes tipos de cursos assemelham-se aos cursos tecnológicos do Brasil.

Mesmo sem utilizar os elementos fundamentais para uma análise criticamente mais aprofundada, Souza (2012) consegue reconhecer que em países da periferia do capital, como no caso do México, a divisão social internacional do trabalho prepondera mais que uma reformulação curricular.

Retomando o fato de o México ter implementado os CSTs a partir da recomendação do Banco Mundial, considera-se que tanto esta quanto as demais sugestões do Banco para os países em desenvolvimento têm sido polêmicas. Esse organismo multilateral é criticado por defender o estabelecimento de um sistema estratificado em termos de criação, acesso e disseminação do conhecimento, segundo o qual países e indivíduos com renda superior deveriam produzir e ter acesso ao conhecimento de alta qualidade, enquanto os de baixa renda deveriam assimilar a produção. (SOUZA, 2012, p. 134).

Takahashi e Amorim (2008) são mais dois pesquisadores otimistas com a aprendizagem por competências "empreendedoras" como meio de formação curricular para as graduações tecnológicas. Esses estudiosos expuseram que a missão do que chamaram de educação tecnológica "superior" é o preenchimento ágil e com qualidade das lacunas de formação de mão de obra. Tais brechas são decorrências, conforme sugerem os autores, das novas necessidades do mercado de trabalho que, por sua vez, são exigências da "globalização 


\section{Trabalhonecessário}

Issn: 1808 - 799X

ano 13, número $21-2015$

econômica que demanda do trabalhador novas competências e habilidades". (TAKAHASHI; AMORIM, 2008, p. 217).

Com o intuito de debater o papel organizador do Estado na promoção das políticas públicas de reformulação da educação, em atendimento à expansão do ensino profissionalizante, especialmente os cursos superiores de tecnologia, Takahashi e Amorim (2008) defendem que esse tipo de graduação precisa atender a qualificação e requalificação da mão de obra. A respeito de uma avaliação das políticas públicas para a educação profissional tecnológica de nível superior, os autores assim se pronunciam: "Trata-se de verificar se existe uma conexão entre o polo demandante de mão-de-obra tecnológica de nível superior no mercado de trabalho e se esta conexão é boa". Concluindo, eles consideram que "um ponto-chave nesta integração é a detecção das competências profissionais demandadas no mercado e como elas podem ser desenvolvidas no âmbito dos cursos oferecidos pelas IES". (TAKAHASHI; AMORIM, 2008, p. 222, grifos nossos).

Ora, se a perspectiva for a do empresariado, sobretudo os fixados nos países produtores de tecnologia, ávidos por garantir seus lucros, a pedagogia das competências pode até, em certa medida, atender ao que Takahashi e Amorim (2008) chamam de economia baseada no conhecimento (EBC) ${ }^{8}$ - categoria afiliada aos mesmos genes que conceberam a suposta sociedade do conhecimento tecnológico. Entretanto, vale a pena fazer a seguinte indagação: quando o ponto de vista for a formação integral dos trabalhadores, será que esse conjunto de inovações pedagógicas poderá resolver os agudos problemas educativos vivenciados hoje pela escola sob as amarras do capitalismo?

\footnotetext{
${ }^{8}$ Freitas (2012) alerta sobre o perigo de o sistema educacional brasileiro seguir as diretrizes educacionais que tem como base a meritocracia e os testes de avaliação de alto impacto. Tais diretrizes seguem, guardando as devidas distinções, a mesma orientação teórica da chamada economia baseada no conhecimento.
} 


\section{Trabalhonecessário}

Issn: 1808 - 799X

ano 13, número $21-2015$

\section{Pedagogia das competências: breve revisão crítica conceitual}

Não podemos nos aproximar de uma conceituação crítica da pedagogia das competências sem antes recorrer, mesmo que sumariamente, à história recente das reformulações patrocinadas pelos organismos internacionais nos países da periferia capitalista. Esse patrocínio induz o pensamento pedagógico local a redesenhar a educação brasileira sob uma teoria que se embasa nas orientações advindas das agências multilaterais. Tal orientação, por sua vez, tem como premissa básica readequar o processo educativo aos imperativos da produção, vinculado por intermédio de mediações múltiplas e complexas aos interesses do capital no contexto de sua crise estrutural (MÉSZÁROS, 2000). A pedagogia das competências, portanto, acaba por ser apropriada para o quadro de crise sob o qual se estruturam as reformulações educacionais brasileiras. A proposta pedagógica em questão segue, em última instância, alguns componentes do ideário do capitalismo em crise profunda, a saber: a teoria do capital humano, a "sociedade do conhecimento" e o determinismo tecnológico.

A fim de contemplar a premissa de que a pedagogia das competências está articulada à tese da existência de uma "sociedade do conhecimento" e, desta feita, circunscrita numa suposta era tecnológica, optamos por começar a discussão das chamadas competências aludindo resumidamente à conferência sobre o "Investimento em capital humano" de autoria de Theodore Schultz. Para esse autor, os sujeitos devem ter um bom aproveitamento do investimento educacional que aplicam sobre si. Outro economista, o também estadunidense Gary Stanley Becker, nos anos 1980, desenvolveu e aprofundou as concepções de Schultz até chegar ao conceito lapidado, conhecido pela sociologia da educação como teoria do capital humano. Não é por acaso que os organismos internacionais, principalmente o Banco Mundial (BM) e o Fundo Monetário 


\section{Trabalhonecessário}

Issn: 1808 - 799X

ano 13, número $21-2015$

Internacional (FMI), adotaram esse fundamento teórico como base para os currículos escolares, sobretudo aqueles ligados ao ensino profissionalizante (SANTOS; JIMENEZ; MENDES SEGUNDO, 2011).

Distinta da teoria do capital humano, filha legítima de Theodore Schultz, embora com boa inspiração em Francis Bacon (saber é poder), a chamada tese da sociedade do conhecimento não atende por uma única paternidade. Para Marise Ramos (2002) o autor dessa tese seria Alvin Toffler, em "A terceira onda", cuja argumentação teria decretado o término das classes sociais e do proletariado, que agora seria substituído pelo cognitariado. Já Neize Deluiz (1995) lembra que, no início dos anos de 1970, Daniel Bell teria adotado esse conceito, referindo-se à sociedade pós-industrial. Essa sociedade, conforme escreve a autora a partir dos apontamentos de Bell, organiza-se em torno de conhecimentos que procuram "obter o controle social e a direção da inovação e da mudança". (DELUIZ, 1995, p. 32).

Nesse contexto, relembramos com Santos, Jimenez e Segundo (2011) o que registrou Lessa (2008): a premissa essencial de uma suposta sociedade do conhecimento remonta à Antiguidade grega e vem, ao longo do tempo, mantendo sua vinculação ideológica com o projeto da classe dominante. Como aponta Vieira Pinto (2008, p. 41), talvez possa se dizer, "com valor de lei sociológica, que os serviçais em todos os tempos pensam analogamente". Em consonância, Lessa (2008, p. 31) afirma que as mistificações em torno de uma suposta sociedade do conhecimento acabam reaparecendo nas "formulações contemporâneas de um Lojkine ou de um Adam Schaff, para ficarmos com alguns autores que são quase sempre considerados de esquerda".

Para que nossa análise possa se distanciar dos exames sobre esse debate, que abordam acriticamente a questão das competências, entendemos que não podemos tratar esse assunto sem rever algumas reflexões de Harry Braverman (1987), que parte do questionamento sobre o conceito de qualificação média. 


\title{
Trabalhonecessário
}

Issn: 1808 - 799X

ano 13, número $21-2015$

Esse autor sustenta que aumentar a média da qualificação do trabalhador para atender às necessidades do capitalismo que, por seu turno, passa a incorporar a partir do advento da gerência científica "o desenvolvimento da tecnologia e aplicação a ela das ciências fundamentais, [...] não passa de uma tautologia". (BRAVERMAN, 1987, p. 359-61). O autor reconhece, todavia, que há hoje uma quantidade jamais vista de conhecimentos científicos incorporados aos processos produtivos, o que pede uma qualificação/requalificação do trabalhador para que ele possa acompanhar as inevitáveis evoluções tecnológicas associadas à produção. Diante do crescente desenvolvimento das tecnologias e sua incorporação ao processo produtivo, o capitalismo necessita que a classe trabalhadora se submeta à constante qualificação, requalificação e atualização das suas habilidades para melhor operar a produção. Caso essa formação não se realize há um comprometimento direto do processo de valorização do capital, em termos absolutos ou relativos. Mas quem perde primeiramente com essa desvalorização é o capitalismo. Sobre esse debate, Braverman (1987, p. 360) afirma o seguinte:

\begin{abstract}
A massa de trabalhadores nada ganha com o fato de que o declínio de seu comando sobre o processo de trabalho está mais que compensado pelo comando crescente por parte dos gerentes e engenheiros. [...] Pelo contrário não apenas sua qualificação cai em sentido absoluto (naquilo que perdem o ofício $e$ as capacitações tradicionais sem ganhar novas capacidades adequadas para compensar a perda), como cai ainda mais num sentido relativo.
\end{abstract}

Nos anos seguintes ao pós-guerra determinados postos de empregos foram estimulados pela demanda crescente de mão de obra especializada e específica para tais profissões. Sérgio Grácio (1986) chegou a conceituar essa demanda como de procura otimista pelo emprego, que se processava principalmente nas carreiras gerenciais e semigerenciais, entre outras, que não estavam disponíveis no mercado para os patrões; no momento que estes 


\section{Trabalhonecessário}

Issn: 1808 - 799X

ano 13, número $21-2015$

necessitassem daquelas. Para esse percurso e, considerando a realidade dos Estados Unidos, Braverman (1987) recupera o alargamento da idade escolar, relacionando o tempo de permanência na escola às necessidades do capitalismo. Ele indica haver, para esse período, importantes subsídios estatais direcionados para a educação do trabalhador. As inferências do analista estadunidense é que o mercado de trabalho, por sua vez, acabou por encontrar um número de trabalhadores com diploma de nível superior acima da capacidade de absorção pelas empresas. Braverman (1987, p. 370) escreve que "pelos fins da década de [19]60 começou a manifestar-se um excesso" de profissionais formados pelo ensino superior, mas sem ocupação direta.

Com base na conjuntura descrita, Braverman (1987) infere que o conteúdo da educação se deteriora enquanto sua duração aumenta. Esse panorama cria a possibilidade favorável aos empregadores de que o diploma seja utilizado como uma peneira para escolher os candidatos considerados mais aptos para profissões estratégicas na hierarquia de acumulação capitalista. A extrema concentração desses conhecimentos, ainda segundo esse autor, "nas mãos da administração e suas organizações de equipes associadas", fecha a via de acesso a uma formação que melhor desenvolva as potencialidades da classe trabalhadora. Para esta classe a situação piora, pois a oferta educativa entregue aos trabalhadores têm por base a "ressignificação" dolorosa e inadequada do conceito de qualificação: "uma habilidade específica, uma operação limitada e repetitiva, a velocidade como qualificação". (BRAVERMAN, 1987, p. 375, grifos nossos). Com esse debate, o autor relaciona a escola à indústria capitalista e suas demandas, concluindo o seguinte: 


\section{Trabalhonecessário}

Issn: 1808 - 799X

ano 13, número $21-2015$

que saber o operário menos precisa de saber, nas escolas que as massas de futuros trabalhadores frequentam quanto mais há para aprender, tanto menos razão há para os professores ensinarem e para os alunos aprenderem. (BRAVERMAN, 1987, p. 372).

As reflexões de Braverman (1987) nos permitiram compreender melhor e com maior posicionamento crítico o que a revisão da literatura sobre o paradigma da competência revela. Como veremos a seguir, a revista sobre o tema indica que ele vem sendo sistematicamente abordado no contexto da chamada reestruturação produtiva, adquirindo o status de ser referenciado à qualificação. Entre os dois conceitos, mesmo que em diferentes graus, via de regra e independente da abordagem, verifica-se que há uma aproximação, um distanciamento, uma distinção, ou uma "ressignificação".

Um importante registro sobre os fundamentos teóricos da pedagogia das competências foi anotado por Nomeriano (2007), cuja pesquisa detectou que, no trato com a questão, um grupo considerável de pesquisadores tem como ponto de partida as investigações do sociólogo francês e especialista em sociologia do trabalho, Phillippe Zarifian. Segundo a autora ele foi o pesquisador pioneiro no estudo sistemático, formalizando cientificamente um conceito sobre a competência. Para Zarifian (2003) competência é uma forma de qualificação em desenvolvimento. Sem esconder seu entusiasmo com a proposta, o autor entende que submetendo o trabalhador a esse paradigma o operário acaba recebendo uma dupla qualificação, primeiramente, como explica, "em relação à sua contribuição para a eficiência de um processo de produção" e, posteriormente, em relação "ao seu lugar na hierarquia salarial". Para o autor, não se deve distinguir conceitualmente qualificação e competência; na verdade, em suas palavras, "o modelo da competência especifica, hoje, de maneira nova, a construção da qualificação". (ZARIFIAN, 2003, p. 37, grifos nossos).

No Brasil, no entanto, um grupo também quantitativamente relevante segue as orientações do sociólogo suíço Phillippe Perrenoud, embora nesse caso, em 


\section{Trabalhonecessário}

Issn: 1808 - 799X

ano 13, número $21-2015$

sua quase totalidade, desprezem as possibilidades adquiridas com a crítica. Acreditamos que a "Revista Nova Escola" seja uma das maiores responsáveis por tal fato. Em sua edição de agosto de 2002, essa revista publicou a matéria intitulada "Os novos pensadores da educação", que virou "coqueluche" entre os educadores brasileiros, ao expor, sob sua ótica, aqueles que seriam os novos "gurus" para os professores dos países periféricos no século XXI. Além do intelectual suíço, a matéria valorizava o trabalho de Edgar Morin, César Coll, Antônio Nóvoa, Fernando Hernández e Bernardo Toro.

Para justificar a inclusão de Perrenoud nessa lista, a revista revelou que o sociólogo vendeu mais de 80 mil livros somente nos dois primeiros anos deste século. Um dos principais motivos desse sucesso, ainda segundo o periódico, foi o lançamento da obra "Dez novas competências para ensinar", lançada no Brasil pela editora Artmed, em 2000. Nela o teórico ensina para os professores a fórmula para atingirem o sucesso do aprendizado em dez passos, são eles: 1) organizar e dirigir situações de aprendizagem; 2) administrar a progressão das aprendizagens; 3) conceber e fazer evoluir os dispositivos de diferenciação; 4) envolver os alunos em suas aprendizagens e em seu trabalho; 5) trabalhar em equipe; 6) participar da administração escolar; 7) informar e envolver os pais; 8) utilizar novas tecnologias; 9) enfrentar os deveres e os dilemas da profissão; 10) administrar a própria formação. Caso essas dez competências não resolvam todos os problemas da escola, o pesquisador suíço alerta para que o professor lance mão da sensibilidade e da afetividade em sala de aula.

Antes de esclarecer qual definição Perrenoud apresenta para competência, a revista diz que um dos pontos mais conhecidos do autor é "a faculdade de mobilizar um conjunto de recursos cognitivos (saberes, capacidades, informações etc.) para solucionar uma série de situações". O principal ponto motivador para o elevado êxito desse sociólogo entre os professores brasileiros, segundo informa a matéria, é o fato de suas ponderações serem apresentadas de "forma clara e 


\title{
Trabalhonecessário
}

Issn: 1808 - 799X

ano 13, número $21-2015$

explicativa, sobre temas complexos e atuais, como formação, avaliação, pedagogia diferenciada e, principalmente, o desenvolvimento de competências". (REVISTA NOVA ESCOLA, 2002, p. 21).

Freres e Holanda (2011) apresentaram um panorama crítico sobre a matéria citada. Para as autoras, embasado sobre uma suposta crítica da "incapacidade" do processo escolar, Perrenoud entende que nas competências estaria guardado o místico poder de ocupação do espaço escolar perdido pelo conhecimento acumulado pela humanidade que se complexifica com o estágio atual de crise crônica do capital. As pesquisadoras refletem que aquele autor enxerga nesse novo paradigma uma espécie de resposta ao antigo problema da necessária transmissão de conhecimentos e que ele poderia fazer a ligação entre os conhecimentos transmitidos pela escola com a vida cotidiana do estudante.

\begin{abstract}
Além disso, este autor [Perrenoud] valoriza o saber prático voltado para o desenvolvimento de habilidades necessárias à resolução de problemas cotidianos, bem como aqueles saberes valorativos relacionados ao saber conviver com um desempregado, um imigrante, um portador de deficiência, uma mãe solteira, um jovem da periferia. Nesse sentido, propõe uma mudança na postura e no papel do professor, que só pode ser possível se a escola diminuir o peso dos conteúdos para que o docente trabalhe os saberes fundamentais para a autonomia das pessoas (saber-dialogar, saber-negociar, saber-utilizar as diferentes tecnologias etc.). Para ele, mais valem os saber-fazer gerais do que o conhecimento acumulado historicamente. (FRERES; HOLANDA, 2011, p. 40).
\end{abstract}

Para que nossa revisão sobre o debate tenha melhor sustentação, examinaremos um pequeno grupo de pesquisadores que desenvolveu suas pesquisas no entorno do Laboratório George Friedmann, da Universidade Paris I (Sorbonne), considerado um dos principais articuladores teóricos da transição da categoria competência da sociologia para a educação.

Iniciamos com Elizabeth Dugué (2004), que localiza o surgimento da noção de competência no cenário das transformações produtivas da década de 1990, 


\section{Trabalhonecessário}

Issn: 1808 - 799X

ano 13, número $21-2015$

representando uma contrapartida ao conceito de qualificação - estreitamente ligado ao taylorismo - que se encontrava em crise. Já Richard Wittorski (2004) concorda com o fato de que o esgotamento do taylorismo teria provocado o fenômeno que desemboca no deslocamento da qualificação em direção à noção de competência. O autor faz questão de apontar que esse deslocamento é muito mais um processo do que um estado.

As pesquisadoras Béatrice van der Heijden e Gildas Barbier (2004), por sua vez, direcionam suas análises para esclarecer a relação criatividade/adaptação em articulação com o problema da competência. Admitem, inicialmente, que "a performance excepcional está geralmente fundada em conhecimentos básicos muitos amplos, assimilados durante um longo processo de aprendizagem". Em seguida, no entanto, consideram que "diante das rápidas evoluções tecnológicas, é importante manter uma distância de acumulação das competências". As autoras avaliam ser utópico imaginar o trabalhador de hoje prevendo uma carreira profissional estável. Para elas, esse novo trabalhador precisa se manter empregável e, para isso, necessita da manutenção "de um alto padrão de performance em toda e qualquer circunstância". Com efeito, sustentam propositivamente que "o trabalhador moderno deve possuir enormes capacidades adaptativas". (HEIJDEN; BARBIER 2004, p. 68).

Em perspectiva distinta da abordagem das autoras supracitadas, Mireille Dadoy (2004), discursando sobre a gênese do termo, explica que "a noção de competência vem do latim competentia, derivada, por sua vez, de comptere, o que significa chegar ao mesmo ponto", oriunda, por seu turno, de petere, sinônimo de "dirigir-se para"; refere-se a "o que convêm"; no francês antigo significava "apropriado". Já a utilização da expressão pelo senso comum corresponde, em linhas gerais, ao reconhecimento sobre a capacidade para efetuar ações com sucesso (DADOY, 2004, p. 108, grifos no original).

Como esclarece Dadoy (2004), a noção de competência partiu da esfera 


\section{Trabalhonecessário}

Issn: 1808 - 799X

ano 13, número $21-2015$

do direito até que, por intermédio do plano linguístico, foi aplicada a objetos diferentes em contextos muito diversificados e com acepções particulares. $\mathrm{Na}$ França, a chegada ampla dessa noção na esfera do trabalho teria ocorrido, segundo a autora, por volta da primeira metade da década de 1980. Daí para o diálogo com o campo educativo não houve muita demora. Cinco anos depois algumas pesquisas já registravam que o discurso dos empregadores adotava a expressão "competência" em detrimento do vocábulo "qualificação". Aquele conceito, em seguida, propagou-se "ainda mais facilmente pelo fato de a palavra retirar dele conotações muito fortes, que não são sempre conscientes para o público". Fato que assegurou à expressão "competência" alta aceitação de assalariados e seus sindicatos, bem como dos patrões. Para Dadoy (2004), essa elevada aceitação ocorre entre aqueles "pelo fato de que, até então, ela era, sobretudo, utilizada para falar dos quadros de executivo"; já para os empresários, a noção de competência foi ainda mais prontamente aceita, pois os patrões perceberam que esse conceito "exalava um perfume de competitividade". Admite a autora que essa noção acabou se revelando "muito mais utilizada em favor dos interesses dos empregadores, em detrimento dos interesses assalariados" (DADOY, 2004, p. 122).

Foi através da seleção de pessoal e da ergonomia cognitiva que se processou o desenvolvimento do conceito das competências, facilitando o seu perfeito cruzamento com as necessidades empresariais, pois, como explica Dadoy (2004), as empresas utilizaram a expressão para designar os saberes e o saber-fazer destinados a tarefas específicas, particulares de cada posto de trabalho e intransferíveis para outras atividades.

Ora, hoje, as análises de competência, tais como são praticadas, ressaltam muito a bricolagem intelectual; ainda procedem muito pelos procedimentos declarativos e não repousam sobre verdadeiras investigações, fundadas sobre ferramentas indiscutíveis. Longe de terem rompido com as técnicas anteriores, 


\section{Trabalhonecessário}

Issn: 1808 - 799X

ano 13, número $21-2015$

apesar das mudanças de vocabulários, elas acabam por desempenhar um papel mais ideológico que técnico. Em contrapartida, têm, perfeitamente, pelo menos até o momento, favorecido os projetos das empresas, permitindo individualizar os procedimentos de avaliação e de remuneração dos assalariados. (DADOY, 2004, p. 139).

Esse parágrafo conclusivo das considerações da autora é suficientemente enfático sobre as fragilidades investigativas que cercam o tratamento dado a questão, bem como seu caráter abertamente apologético em favor de uma suposta nova orientação empresarial. Dito de outra forma, o chamado paradigma das competências é mais um aparato ideológico utilizado pelo capital que ganha foro privilegiado dentro da educação, destacadamente no currículo da educação profissionalizante e, de modo especial, na graduação tecnológica.

Quando posicionamos o debate sobre a pedagogia das competências no Brasil não podemos deixar de destacar, em primeiro plano, o rigoroso trabalho investigativo de Marise Ramos (2006), que posiciona criticamente o paradigma das competências como a "pedagogia da Sociedade do Conhecimento, da Sociedade Pós-Industrial ou da Sociedade Pós-Moderna". Com efeito, esses três componentes se interligam para compor o amálgama que dá base teóricoepistemologicamente a esse paradigma. Na esteira aberta por Zarifian (2003), Ramos (2006) entende que a gestão por competência seria composta pelos seguintes elementos: 1) gestão individualizada dos trabalhadores no quadro dos objetivos das empresas; 2) desenvolvimento das competências individuais; 3) reconhecimento das competências adquiridas pelo trabalhador; e 4) remuneração em função dessas competências.

Referindo-se à relação entre as noções de qualificação e de competência, a autora posiciona-se ao lado daqueles pesquisadores que identificam a ocorrência de um deslocamento conceitual da primeira para a segunda categoria, aferindo, mais precisamente, que a centralidade histórica daquele conceito, "no ordenamento das relações sociais de trabalho e educação, está sendo 


\section{Trabalhonecessário}

Issn: 1808 - 799X

ano 13, número $21-2015$

tendencialmente ocupada pela noção de competência". (RAMOS, 2006, p. 5). O paradigma da competência seria, na verdade, como acrescenta a autora, "um modelo de gestão capaz de organizar a tensão entre conhecimentos e competências, permitindo, assim, ultrapassar o falso dilema entre qualificação do emprego e qualificação do indivíduo". (RAMOS, 2006, p. 12).

Para melhor esclarecer seus pontos de vista sobre a relação indivíduo/cargo versus desempenho, Ramos (2006) dialoga com as reflexões de Rogério Valle, trazendo para o debate o seguinte registro: "as competências poderiam ser vistas como a mediação entre a qualificação e o desempenho no cargo, podendo explicar, por exemplo, porque indivíduos com a mesma formação têm desempenhos diferentes num mesmo cargo". (RAMOS, 2006, p. 12).

Como forma de problematizar as principais contradições da pedagogia das competências, Ramos (2006) apresenta, mediante debate com Yves Schwartz, algumas de suas principais conclusões, reafirmando o caráter insuficiente do referido paradigma. Ela indica haver, no horizonte da emancipação, limites quanto ao enfrentamento das contraditórias relações entre o trabalhador, o processo de construção do saber e as condições materiais do trabalho:

Concluímos, então, que a questão fundamental que reside no conceito de qualificação como relação social não é enfrentada pela noção de competência: compreender o movimento dinâmico e contraditório da construção e do uso dos saberes pelos trabalhadores, bem como o jogo relacional que se processa entre eles e deles com a materialidade objetiva do trabalho. Processo esse que transforma o trabalho vivo em trabalho morto, mas que também potencializa lutas sociais no sentido da emancipação do trabalhador, à medida que ele se torna efetivamente o sujeito das relações de trabalho (RAMOS, 2006, p. 16, grifo nosso).

É inegável o avanço crítico posto às claras nas análises de Ramos (2006). A autora situa suas ponderações em uma linha de denúncia devidamente fundamentada no que se refere ao deslocamento conceitual do paradigma da 


\section{Trabalhonecessário}

Issn: 1808 - 799X

ano 13, número $21-2015$

qualificação, rumo ao estabelecimento da competência, rigorosamente desfavorável ao trabalhador e a um projeto de educação emancipatório. Por outro lado, a linha de chegada para onde aponta a análise da autora estaria situada em um ponto nevrálgico que precisa ser necessariamente ressalvado. Esse nervo causador do "mal-estar" refere-se à possibilidade indicada por Ramos (2006) de uma possível reversão do referido deslocamento. Ela entende que esse processo é um projeto ainda em disputa na esfera da política e, sendo assim, os trabalhadores teriam chances de lograrem êxito nesse pugilato. A citação que se segue é da própria autora e acreditamos que através de sua leitura o leitor compreenderá melhor o que estamos objetando no pensamento de Ramos (2006, p. 20):

procuramos apreender a essência do deslocamento conceitual [da qualificação à competência] como processo contraditório e que, por isso, não está definitivamente determinado em favor da classe dominante. Pode sim, ser reapropriado pela classe trabalhadora a partir de seus motivos e conferindo-lhe seus significados.

Um interessante aprofundamento crítico foi apresentado por Nomeriano (2007), que procurou demonstrar os limites do debate empreendido por Ramos (2006) à pedagogia das competências, não deixando de reconhecer o mérito inconteste da análise desta pesquisadora ao delatar o caráter individualista e desagregador do modelo ancorado na noção de competência. Por outro lado, Nomeriano (2007) aponta o ineliminável atrelamento da pedagogia das competências ao projeto de reprodução do capital no contexto da crise contemporânea. Em acordo com as inferências desta autora, reconhecemos que a pedagogia das competências, como todo o conjunto dos chamados novos paradigmas educacionais, cada um a seu termo, é uma necessidade, não uma disfunção que possa ser resolvida na luta política travada dentro das amarras capitalistas. 


\section{Trabalhonecessário}

Issn: 1808 - 799X

ano 13, número $21-2015$

\section{Notas conclusivas}

Como tentamos deixar claro ao longo da exposição, apesar do reconhecido caráter polêmico da pedagogia das competências, textos oficiais e alguns estudiosos sobre o tema não escondem seus elogios sobre tal paradigma. Isso nos permite inferir que é inegável a força de convencimento que tal proposta exerce sobre grande parte dos educadores e intelectuais, sobretudo os profissionais que trabalham com a chamada educação profissional e tecnológica. Nossa exposição, por tratar da expansão não universitária do ensino superior, não pode deixar de examinar os elementos mais críticos a respeito dessa proposta pedagógica, mesmo que apenas em determinado recorte, pois seus determinantes, como tivemos oportunidade de anotar, dão tecitura aos novos arranjos presentes na educação superior.

Portanto, como forma de melhor articular a hipótese levantada em nossa introdução, buscamos ao longo da discussão aqui apreendida posicionar o debate acerca da invasão de alguns preceitos empresariais sobre o campo educacional. Primeiramente, verificamos alguns documentos oficiais, bem como algumas pesquisas que compreendem essa proposta como uma boa alternativa para a escola do trabalhador. Posteriormente, analisamos a proposta das competências com um pouco mais de profundidade, o que nos permitiu indicar suas principais debilidades. Com essa problemática aclarada, reunimos condições de apontar que a expansão precária do ensino superior - pela via não universitária - se entrecruza em vários aspectos com essa pedagogia.

É interessante relembrar que essa proposta educacional, aliás, é uma "ressignificação" dos ideários tecnicistas implantados no Brasil "a ferro e fogo" pelas amarras terroristas da ditadura empresarial-civil-militar, iniciada nos anos de 


\section{Trabalhonecessário}

Issn: 1808 - 799X

ano 13, número $21-2015$

1960. Tal implantação se deu por intermédio do acordo estabelecido entre o Ministério da Educação e Cultura (MEC) e a United States Agency for International Development (USAID), denominados Acordos MEC-USAID. Contudo, foi a partir dos desdobramentos da crise do capitalismo contemporâneo que o capital necessitou encontrar novas apostas para gerenciar seus problemas. Diante desse contexto, a pedagogia das competências é apontada como o novo epicentro curricular do modelo de formação do trabalhador. Fortemente favorável ao empreendedorismo empresarial, em detrimento de uma formação que aponte para a integralidade do ser humano, o paradigma das competências torna-se o parâmetro indispensável à formação especificamente imediatista para um ofício, visto que na visão de seus defensores capacita mão de obra para habilidades empreendedoras necessárias ao preenchimento das lacunas do mercado de trabalho. Entretanto, o que não é esclarecido pelos defensores dessa proposta educativa é que ela se ajusta melhor às intermitências capitalistas, cujo estágio de profundidade de sua crise não pode dispensar o "nicho" de mercado representado hoje pela educação, especialmente a superior.

Nesse elenco que compõe o desejo empresarial de atar educação ao mercado, os empresários e seus artifícios acenam, como contrapartida para o trabalhador, 0 aumento de sua empregabilidade, 0 desenvolvimento das criatividades individuais, a potencialização empreendedora e o dinamismo dos saberes subjetivos. Ademais, enfatizam os agentes que advogam um currículo para o trabalhador moldado ao gosto do mercado, entre um refinado rol de expressões prontas e acabadas na ponta da língua, que o "novo" empregado formado sob o manto das competências terá mais flexpertise para enfrentar o atual quadro de crise/oportunidade. No caso específico da retrógrada elite brasileira, pretende-se "impor uma visão ideológica do ideal de novo empregadocidadão em que o trabalhador é obrigado a se transmutar para sobreviver - via de regra, de forma precária - no contexto da crise hodierna". (SANTOS; JIMENEZ; 


\section{Trabalhonecessário}

Issn: 1808 - 799X

ano 13, número $21-2015$

MENDES SEGUNDO, 2011, p. 33).

Por fim, devemos esclarecer que, se por um lado estamos cientes de nossos limites em abarcar uma polêmica com a envergadura que cerca esse debate - o que nos permite apenas apontar alguns elementos para futuros aprofundamentos -, conforta-nos, por outro lado, declarar que não nos interessa deixar alguma dúvida sobre qual o posicionamento de nossa pesquisa a respeito de tal paradigma educativo. Assim, assinalamos que a pedagogia das competências cumpre adequadamente o papel de revigorar a teoria do capital humano no contexto das propaladas "era tecnológica, sociedade do conhecimento, sociedade da informação", entre outros termos. Com efeito, a proposta denominada pedagogia das competências aparece com o objetivo de favorecer a fragmentação, a flexibilização, a polivalência, o aligeiramento, no meio do enorme contingente de "novas" formas de precarizar a formação do trabalhador. Apesar das "novas" ações sobre o currículo para o ensino universitário - dentro do contexto de expansão do ensino superior pela via não universitária -, essa proposta pedagógica vem ao encontro das necessidades do capital em crise profunda, visto que atende em grande monta ao currículo das chamadas graduações tecnológicas que, por seu turno, se molda aos imperativos imediatistas empresariais das agências transnacionais.

\section{Referências}

BRASIL. Ministério da Educação. Conselho Nacional de Educação. Parecer CEB $n^{\circ}$ 16/99: Diretrizes curriculares, nível técnico. Brasília, DF, 1999. Disponível em: $<$ http://portal.mec.gov.br/setec/arquivos/pdf_legislacao/tecnico/legisla_tecnico_par ecer1699.pdf>. Acesso em: 21 mar. 2012.

. Ministério da Educação. Conselho Nacional de Educação. Parecer $C P n^{\circ}$ 29/02: Diretrizes curriculares, nível tecnológico. Brasília, DF, 2002. Disponível em: 


\section{Trabalhonecessário}

Issn: 1808 - 799X

ano 13 , número $21-2015$

<http://portal.mec.gov.br/setec/arquivos/pdf_legislacao/superior/legisla_superior_p arecer292002.pdf >. Acesso em: 21 mar. $20 \overline{1} 2$.

- Ministério da Educação. Conselho Nacional de Educação. Resolução CP

03/02. Brasília, DF, 2002. Disponível em: $<$ http://portal.mec.gov.br/cne/arquivos/pdf/CP032002.pdf>. Acesso em: 20 mai. 2014.

. Ministério da Educação. Conselho Nacional de Educação. Parecer CES $\mathrm{n}^{\circ}$ 277/06. Brasília, DF, 2002. Disponível em: <http://portal.mec.gov.br/cne/arquivos/pdf/pces277_06.pdf>. Acesso em: 20 mai. 2014.

. Presidência da República/ Casa Civil. Lei $n^{\circ}$ 11.741/2008. Brasília, DF,
2002. Disponível em: <http://www.planalto.gov.br/ccivil_03/_Ato20072010/2008/Lei/L11741.htm>. Acesso em: 20 mai. 2014.

BRARVERMAN, Harry. Trabalho e capital monopolista: a degradação do trabalho no século XX. Rio de Janeiro: Guanabara, 1987.

DADOY, M. As noções de competência e competências à luz das transformações na gestão da mão de obra. In: TOMASI, A. Da qualificação à competência: pensando o século XXI. São Paulo: Papirus, 2004.

DELUIZ, N. Formação do trabalhador: produtividade e cidadania. Rio de Janeiro: Shape, 1995.

DUGUÉ, E. A lógica da competência: o retorno do passado. In: TOMASI, A. Da qualificação à competência: pensando o século XXI. São Paulo: Papirus, 2004.

FREITAS, Luiz Carlos de. Os reformadores empresariais da educação: da desmoralização do magistério à destruição do sistema público de educação. Educação e Sociedade, Campinas, v. 33, n. 119, p. 379-404, abr.-jun. 2012. Disponível em: <http://www.scielo.br/scielo.php?script=sci_pdf\&pid=S0101 73302012000200004\&lng=en\&nrm=iso\&tlng=pt>. Acesso em: 20 mar. 2014.

FRERES, Helena de Araújo; HOLANDA, Francisca Helena de Oliveira. Os novos pensadores da educação do novo milênio: uma análise à luz da crítica marxista. Revista Eletrônica Arma da Crítica. Fortaleza, ano 3, n. 3, dez. 2011.

GRÁCIO, Sérgio. Política educativa como tecnologia social: as reformas do ensino técnico de 1948 e 1983. Lisboa: Livros Horizonte. 1986.

HEIJDEN, B; BARBIER, G. A competência, sua natureza e seu desenvolvimento: uma abordagem anglo-saxônica. In: TOMASI, A. Da qualificação à competência: pensando o século XXI. São Paulo: Papirus, 2004.

LESSA, Sergio. Trabalho e luta de classes na "sociedade do conhecimento". In: JIMENEZ, S. et al. Marxismo, educação e luta de classes: teses e conferências do II Encontro Regional Trabalho, Educação e Formação Humana. Fortaleza: EdUECE/IMO, 2008.

. Capital e Estado de bem-estar: o caráter de classe das políticas públicas. São Paulo: Instituto Lukács, 2013.

LIMA, Ricardo Cirino de. Educação tecnológica no Brasil contemporâneo: 


\section{Trabalhonecessário}

Issn: 1808 - 799X

ano 13, número $21-2015$

problematizando a aprendizagem das competências. 2011. Dissertação (Mestrado) - Pontifícia Universidade Católica de Goiás, Goiânia, 2011.

MÉSZÁROS, István. A crise estrutural do capital. Outubro: Revista do Instituto de Estudos Socialistas, São Paulo, n. 4. 2000.

NOMERIANO, A. A educação do trabalhador, a pedagogia das competências e a crítica marxista. Maceió: EdUFAL, 2007.

ORGANIZAÇÃO DAS NAÇÕES UNIDAS PARA A EDUCAÇÃO, CIÊNCIA E CULTURA - Unesco; IESALC. Informe sobre la educación superior en América Latina y el Caribe 2000-2005: La metamorfosis de la educación superior. Caracas, 2006.

PERRENOUD, P. Dez novas competências para ensinar. Porto Alegre: Artes Médicas, 2000.

RAMOS, Marise N. Reforma da educação profissional: uma síntese contraditória da (a)diversidade estrutural. Trabalho apresentado na 19a Reunião Anual da ANPEd, 1996. In: ANPEd 25 anos, CD-ROM histórico, 2002.

. Teorias sociais sobre a competência em educação e trabalho. In: SEMINÁRIO ASPTI. 9., 2006, Universidade do Minho, Braga-Portugal. Braga, 2006.

REVISTA NOVA ESCOLA. Os novos pensadores da educação. São Paulo: Abril, 2002.

SANTOS, Deribaldo; JIMENEZ, Susana; MENDES SEGUNDO, Maria das Dores. O ideário educacional competente no contexto da crise estrutural do capital. Cadernos de Pesquisa em Educação PPGE-UFES, v. 17, p. 9-33, 2011.

SCHULTZ, Theodore W. O capital humano: investimento em educação e pesquisa. Rio de Janeiro: Zahar, 1973.

SOUZA, Juliana Brito de. Política de expansão dos cursos superiores de tecnologia: nova face da educação profissional e tecnológica. 2012. Tese (Doutorado) - Universidade Federal de Minas Gerais, Faculdade de Educação, Belo Horizonte, 2012.

TAKAHASHI, Adriana Roseli Wünsch; AMORIM, Wilson Aparecido Costa de. Reformulação e expansão dos cursos superiores de tecnologia no Brasil: as dificuldades da retomada da educação profissional. Ensaio: Avaliação de Políticas Públicas em Educação, Rio de Janeiro, v. 16, n. 59, p. 207-228, abr./jun. 2008.

VIEIRA PINTO, Álvaro. O conceito de tecnologia. Rio de Janeiro: Contrapontos, 2008.

WITTORSKI, R. Da fabricação das competências. In: TOMASI, A. Da qualificação à competência: pensando o século XXI. São Paulo: Papirus, 2004.

ZARIFIAN, P. O modelo da competência: trajetória histórica, desafios atuais e propostas. São Paulo: SENAC, 2003. 


\section{Trabalhonecessário}

Issn: 1808 - 799X

ano 13, número $21-2015$

Recebido em 12 de maio de 2015.

Aprovado em 25 de julho de 2015. 